\title{
Flipping the Ship: Ocean Waves, Media Orientations, and Objectivity at Sea
}

\author{
Stefan Helmreich (1) ${ }^{a}$ \\ Keywords: hydrocolonialism, waves, orientation, objectivity, oceanography, pacific history \\ https://doi.org/10.1525/001c.21389
}

The FLoating Instrument Platform (FLIP), a seagoing vessel managed by the Scripps Institution of Oceanography, in La Jolla, California, offers an unorthodox vantage point on the sea. In its horizontal conformation, FLIP travels like an ordinary oceangoing craft. But by "flipping" 90 degrees into a vertical position once it arrives at its destination - with all the furniture and instrumentation inside swiveling correspondingly - it becomes an enormous spar buoy, more or less stationary in the wave field. With most of the platform's 108-meter length below the surface, scientists can work in a stable environment, which helps them study sea surface phenomena such as waves against a largely unwavering baseline. This article offers an anthropologically informed media studies account of work on FLIP, as the author reports on working ethnographically alongside wave scientists in this Escheresque environment, a setting that often sees scientists shifting between aspirations to steady objectivism and moments of fleeting but motivating wonder. Placing FLIP in a longer history of physical oceanography, the author also argues that what wave scientists take ocean waves to be has been strongly imprinted by the techniques and technologies - mathematics, photography, spectral analysis, wave tanks - through which waves have been studied and come to be known. Wave science also inherits knowledge from midtwentieth-century ocean observation projects in the Pacific Ocean that were conditioned by Cold War American maritime expansion. The paper suggests that the technological mediations, orientations, and re-orientations offered to scientists at sea on FLIP may serve as allegories for apprehending American oceanography's oscillating visions of the relationship of science to society, of present research to future implications, and of objectivity to politics - visions that come into focus as scientists (and their anthropological interlocutors) switch, alternate, and flip their paradigm scripts, their frames of epistemic reference.

Rising into view from the motorboat I have hired from Marina Del Rey, California, on this October 2017 day is the FLoating Instrument Platform $(F L I P)$, a seagoing research vessel operated by the Scripps Institution of Oceanography at the University of California, San Diego. FLIP is moored thirty-five miles off Malibu, positioned in 600-meter-deep water, floating at coordinates I was emailed last week by the platform's chief scientist. It is a singular vessel, offering an off-kilter vantage point on the sea (figure 1 ). In its horizontal orientation, FLIP can be towed out to sea like an ordinary oceangoing craft. But by "flipping" 90 degrees into a vertical position once it reaches its at-sea destination, it can become an enormous spar buoy, more or less stationary in the wave field, looking like nothing so much as a maritime metal tree house. With seven-eighths of the platform's 108-meter length below

\footnotetext{
a Stefan Helmreich is professor of anthropology at the Massachusetts Institute of Technology. He is author of Alien Ocean: Anthropological Voyages in Microbial Seas (2009) and Sounding the Limits of Life: Essays in the Anthropology of Biology and Beyond (2016). His essays have appeared in Critical Inquiry, Representations, American Anthropologist, The Wire, Cabinet, and Public Culture.
} 


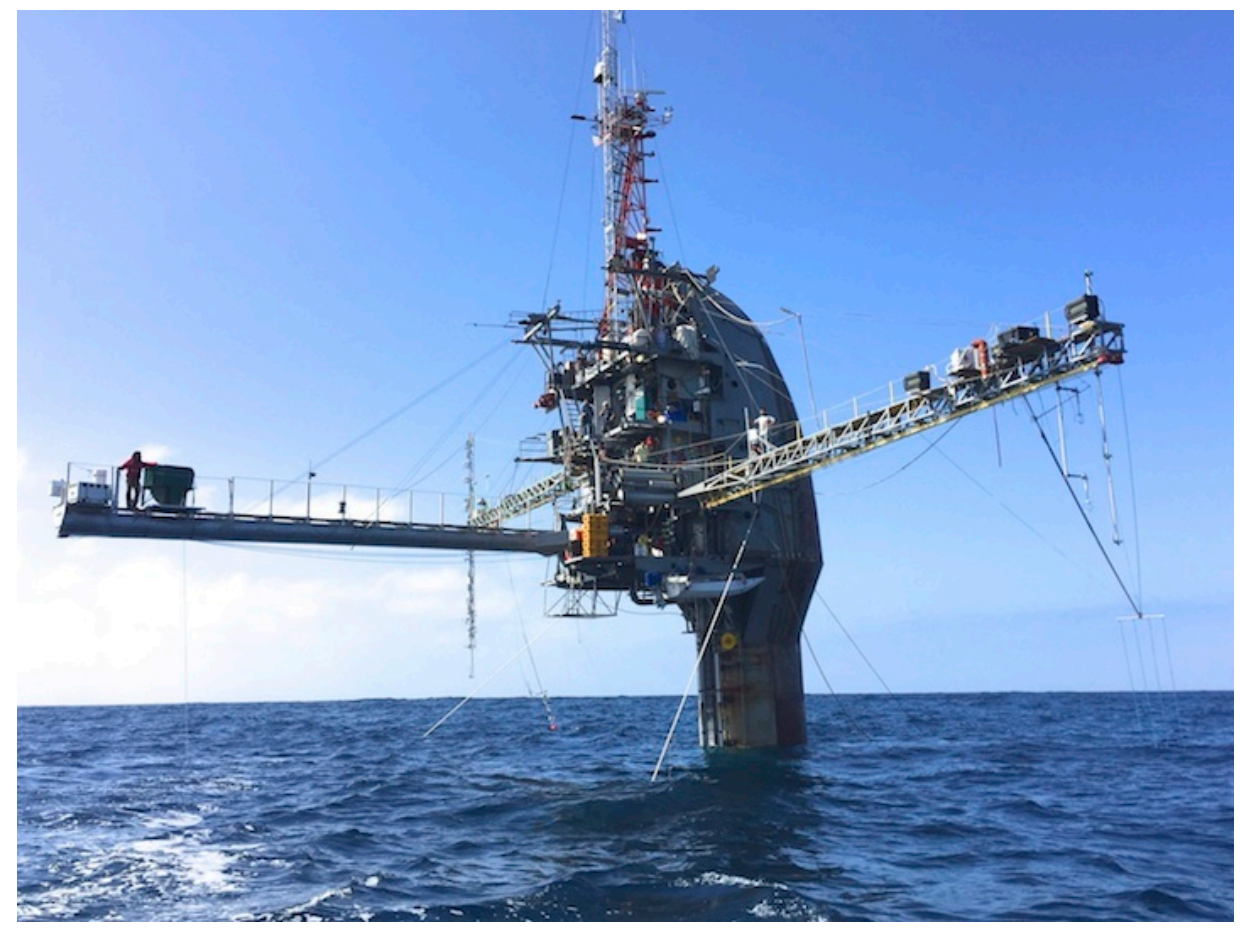

Figure 1: FLIP upright, at sea. Photo by the author.

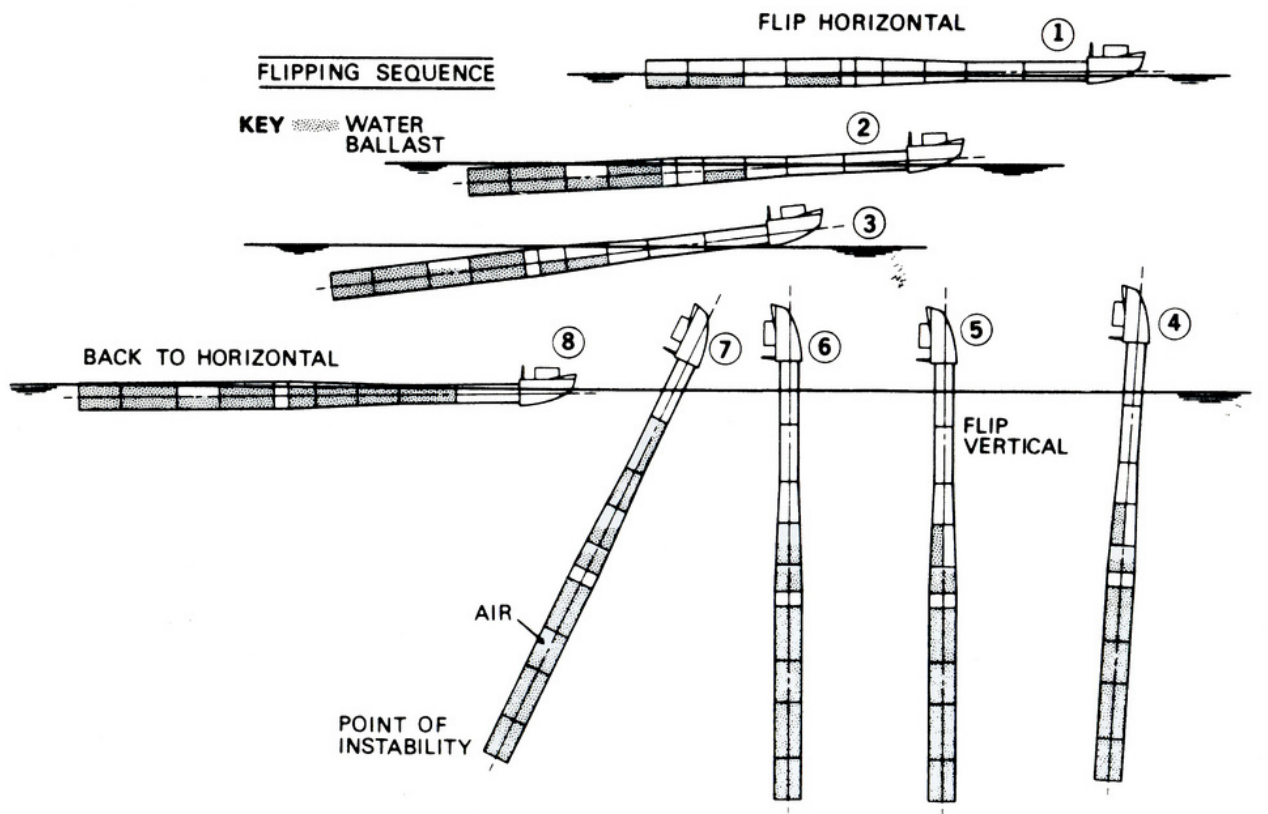

Figure 2: FLIP’s flipping sequence. From Bronson and Glosten 1985, 17, adapted from Fisher and Spiess 1963. Courtesy of Scripps Institution of Oceanography at UC San Diego.

the surface-and all of the furniture and instrumentation inside its top oneeighth swiveled on gimbals by 90 degrees-scientists can study ocean dynamics from a platform with only a slow bob (figure 2). 
I have secured a berth on FLIP to join scientists examining the interface where water meets air, where waves broker the turbulent exchange of heat, gas, and momentum between sea and sky, shaping weather and climate. As an anthropologist, I am interested in how these oceanographers study waves - patterns of force that texture the sea surface, modulate meteorological trends, and sculpt shorelines. And I want to know how they do that work at sea (as opposed to on paper, in computer simulations, or in lab wave tanks-other media through which scientists diagram, model, and make waves). My first observation is that oceanographers study waves in what they call "the field" by seeking to hold their scaffolds of apprehension and analysis still. That is an operation, I argue below, that has them flipping between frames of reference, moving from being wave-tossed (and even seasick) to being aloof, and pivoting, too, from grid-like mathematical accountings to considerations of their work as a source of wonder, a fund for environmental attunement, and a social process rotating in and out of alignment with the "pure" and "applied," which, for oceanography in the United States, has often meant between the oceanographic-meteorological and the military.

The "FLIP ship" is a legend in oceanography, a "one-of-a-kind wonder," says the Smithsonian (Waters 2012). It is FLIP's capacity to flip by 90 degrees that has made it an object of amazement. The platform - not technically a "ship," since it has no propulsion power of its own-puts me in mind of the mind- and gravity-bending lithographs of Dutch artist M. C. Escher, full of sideways doors, swiveling sinks, and tables in dual orientations. Having toured FLIP back in port, on its side, in San Diego, I compare my photos of what rooms look like this way rather than that (figures $3 \mathrm{a}$ and $3 \mathrm{~b}$ ). I recall Ludwig Wittgenstein's storied cartoon duck that becomes a rabbit when one flips one's perception of it, seeing what was, in one frame of reference, a duck's bill becoming rabbit ears in another (figures $4 \mathrm{a}$ and $4 \mathrm{~b}$ ). When I spend my first night on FLIP, I realize that my top bunk faces a ceiling that is, on sideways days, a door. One scientist says it was a relief, after the flip, to "kiss the waves goodbye," to leave seasickness behind as the platform angled upward.

FLIP, built in 1962, is an artifact marked by the last fifty or so years of wave science at Scripps. FLIP came into service a couple of decades after Scripps research on wave prediction for World War II, which unfolded mostly near beaches, aimed at forecasting waves for Allied amphibious landings on Naziheld shores. During the Cold War, Scripps oceanographers turned their attention to the open sea, employing FLIP in studies of how storms transmit surface waves and in research tuned to submarine acoustics (see Fisher and Spiess 1963; Scripps Institution of Oceanography n.d.). FLIP was built just after the Soviet Union launched the Sputnik satellite, which motivated US technoscience to undertake particularly spectacular, often "futuristic" constructions (Rozwadowski 2004). FLIP has been central to making legible to oceanographers and also the military-the vessel, though operated by Scripps, is owned by the US Navy-previously unobserved territories of the sea. In 

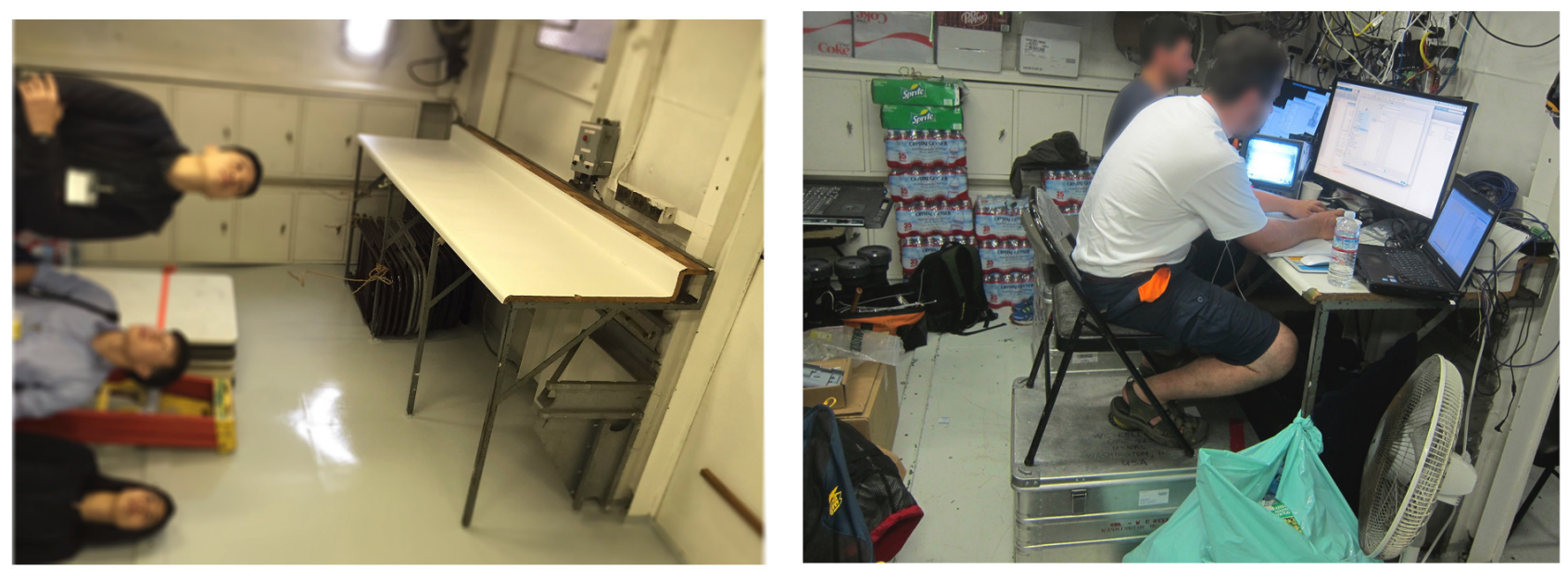

Figures $3 \mathrm{a}$ and $3 \mathrm{~b}$. The FLIP science lab, this way and that. Photos by the author.

\section{Belde zhiere gleiden ein= $\mathfrak{a} \mathfrak{d} \mathfrak{d} \mathfrak{r} \mathfrak{a m}$ meiften?}

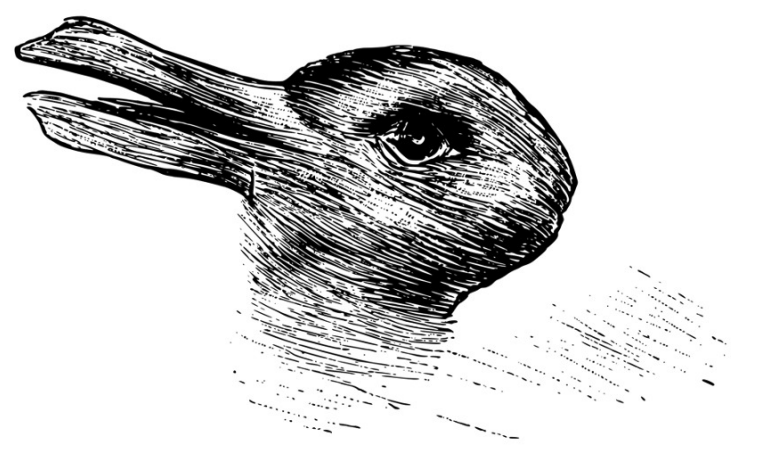

Ranindhen und Ente.

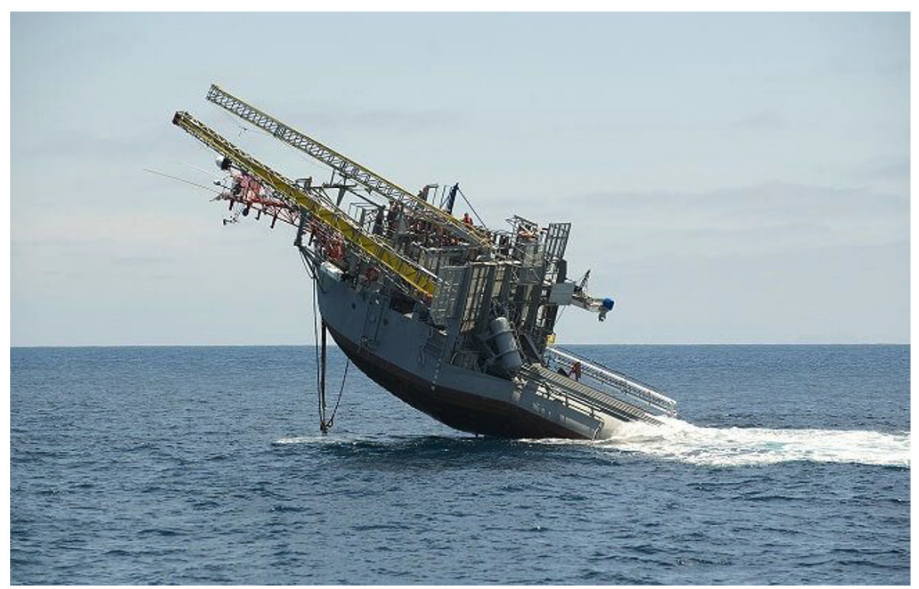

Figure 4a: "Kaninchen und Ente" ("Rabbit and Duck”), from the October 23, 1892, issue of Fliegende Blätter.* Ludwig Wittgenstein adapted this image into his famous duck-rabbit cartoon in Philosophical Investigations $(1953,194)$.

Figure 4b: FLIP in midflip. Photo: John F. Williams, US Navy/CC. Public domain.

${ }^{*}$ Digitized at https://digi.ub.uni-heidelberg.de/diglit/fb97/0147?sid=8af6d821538a1926abf44c9a95c40951\&zoomlevel=2.

recent years, FLIP has become a site for studying how waves break in the open ocean, a matter with relevance for understanding transformations in the atmospheric distribution of carbon dioxide: climate change.

In what follows, I chronicle my stay on FLIP, providing a glimpse of today's seagoing wave science, gesturing along the way to the history of such science, from the Cold War on. Contexts of wave research discovery, motivation, and justification have shifted over the decades, from military to ecological 
concerns, ${ }^{1}$ even as ecological questions inherit framings from prior ocean operations research. Ocean waves, I suggest, have also, across this historical trajectory, become readable to scientists through conceptual schemes made available by media technologies, including time-stepped aerial photography, visualizations of wavelengths in electronic communications (e.g., graphs of the radio spectrum), infrared readings of turbulence, digital imaging, and more. Scientists apprehend waves through mediations, viewing waves (to adapt terms from media theory), as forces of transmission, as patterns that materialize at interfaces (of air and water, of buoys and computer screens), and as mechanisms of inscription (producing traces that can be read, for instance, for evidence of distant storms).

Technological and media forms therefore imprint on how ocean waves manifest as objects of knowledge. That claim is not to deny the use value of such formulations but to place them in cultural history-or, better, to flip a dominant angle of vision on the science, which would discern a bright line between what is discovered and what is formalized about waves. What scientists take waves to be is impressed by the media through which waves become legible. Wave science, to draw on Roland Barthes, is a practice of interpretation in which "the reader is no longer a consumer, but a producer of text" $(1974,4)$.

The first section of this article snapshots workaday life on FLIP. The second offers a historical vignette of how midcentury wave scientists came to see waves as unfurling across a spectrum of frequencies-an understanding that I claim derived in part from researchers' familiarity with electronic media and, for Scripps scientists working in the Pacific as a "laboratory," depended upon the projection and propagation of American power across that ocean. My third and fourth sections return to FLIP, examining scientists' oscillating orientations to wonder and objectivity at sea.

Inspired by the clever backronym that gives FLIP its name, I draw upon a range of meanings of $f$ ip: to cause to turn; to cause to turn over; to turn on or off with a switch; to change from one state to another; to become enthusiastic. The title of this article, "Flipping the Ship," aligns with the sideways turn of thinking that led to the making of the platform but also with the notion of "flipping the script," "making an unexpected or dramatic change, reversing the usual or pre-existing positions in a situation." 2 There are generative ambiguities in the analytic of the flip. Sometimes a flip is a full inversion or reversal.

\footnotetext{
1 See Oreskes 2003 on how contexts of motivation shape questions asked even prior to what philosopher Hans Reichenbach once called scientists' contexts of discovery (which may be serendipitous) and eventual contexts of justification (which name how results are shored up logically).

2 The Oxford English Dictionary points to the hip-hop song "Mecca and the Soul Brother," by Pete Rock and CL Smooth, as the 1991 origin of the phrase. My definitions of flip are adapted from Merriam-Webster and the OED.
} 
Sometimes it is a disorientation or reorientation, though one that may be ultimately captured back into a larger geometry of sense (like a graph in threedimensional, Euclidian, $x, y, z$ space). ${ }^{3}$ All are relevant here.

\section{On FLIP}

My first fieldwork frame-of-reference flip comes when I leap from my waveborne boat onto the steady neck of FLIP. I clamber up the craft's slippery ladder, bloodying my shin even through my jeans, and I meet the nine researchers and five crew members with whom I will spend the next three days. They have been here a few weeks. The chief scientist, Qing Wang, ${ }^{4}$ a professor of meteorology at the Naval Postgraduate School in Monterey, California, greets me, and I learn from her that this stationing of FLIP is part of a sprawling project involving an array of buoys, autonomous underwater vehicles, a twin turboprop plane, and another Scripps ship, the R/V Sally Ride.

This assemblage, Wang tells me, aims to disclose how ocean waves and swells modulate temperature and humidity across the sea surface, modulations that can facilitate or interfere with radio waves. The research will inform the quality of near-sea surface electromagnetic communications (this includes radar, one reason there are some U.S. Navy monies behind this research) as well as contribute to readings of the air-sea interface as an indicator of climate change (see Wang et al. 2019). The naval connection is no surprise. Much Scripps oceanography has, since World War II, been supported by a mix of funds from the National Science Foundation and the Office of Naval Research, even as scientists themselves are not in uniform nor usually much interested in military work. If generations of Scripps oceanographers after World War II came shaped by the adjacency of naval priorities, many students today come to the field because of a love of the ocean (surfing, swimming, boating) and a concern about the ecological health of the sea. ${ }^{5}$

When I received instructions about how to get to FLIP, I was provided with a map revealing a seascape of which I had been ignorant: the Point Mugu U.S. Navy Sea Range, a swath of sea, just off the coast of Los Angeles, dedicated to testing naval maneuvers and technologies. Just outside this space was the instrumented area within which $F L I P$ would assay wavespace. Coming to wave science from my own surfing biography, the military map jolted me into an uneasy genre of wonder at the mathematically, computationally, militaryindustrial, and oceanic sublime. I knew that I was headed into, and writing

\footnotetext{
3 Think of talk in the United States of "flipping the Senate," changing the political party in charge of this body, which points either to epochal shift or to continuity with stable structures of governance.

4 Scientists' real names are used with their permission, as are quotations from my conversations with them.

5 Naomi Oreskes $(2003,730)$, writing of Scripps and the Navy, notes that "as scientists trained students, the interests of the next generation remained weighted towards issues originally driven by Cold War concerns, even after military funding had decreased ... Military concerns were naturalized, and the extrinsically motivated became the intrinsically interesting."
} 
from a privileged position in, "the belly of the beast," that nexus of U.S. scientific and military enterprise that Donna Haraway (1991, 188) has observed is the matrix for so much contemporary technology.

As I settle in on FLIP, it becomes obvious that people are executing tasks in time-bound loops, repeating observations at regular intervals. I come across Dave Ortiz-Suslow, fresh from his $\mathrm{PhD}$ at the University of Miami's Rosenstiel School of Marine and Atmospheric Science. ${ }^{6}$ He stands on a grated metal walkway, studying the waves. I ask him what he sees.

Young waves developing. Westerlies turning on-it's the afternoon sea breeze. It seems like the swell has died a little bit-but you can see a longer oscillation coming in from the Pacific Ocean. And the short waves we see here are going to come and mess things up for everyone trying to surf. You're seeing whitecapping a bit-ten knots is about the cutoff. Nice classic Southern California wave field; this is what we've had every single day. Except during the Santa Ana winds.

Ortiz-Suslow is in charge of a "surface-following meteorological mast" he calls "FLOP," for "FLIP's lowest observation point" (the implied call out to flipflops-California beach footwear descended from the Japanese zori that American servicemen brought back after World War II-places us firmly in a Southern California surf milieu). Tethered to one of the booms, FLOP consists of a pole that has mounted onto it temperature, humidity, and pressure sensors as well as a "motion pack," which, Ortiz-Suslow tells me, measures "linear acceleration and rotation, from which we can extract wave information. We can directly relate that to wave height, and hopefully, with some tinkering, wave direction.” Back inside FLIP, he shows me a computer screen translating that data into a scrolling visualization that shows, in pixeled squiggles, the spectrum of wave energy over the course of the day.

Some squiggles represent the unhurried yawing of FLIP-a side-to-side wobble with a minute-long period. Ortiz-Suslow says this motion will be digitally removed when he cleans up the data. It might take "some time back on shore, in front of the computer, because right now we're also very slightly rotating - back and forth by about 20 degrees every thirty seconds-and that's because the mooring is slightly off. And the keel is pitching by 5 degrees because of currents. The trick will be canceling all this out. You go out for five weeks then spend twenty-four months fixing the data!” FLIP is mostly stationary, but that needs to be further curated in the recordkeeping process. 
This is a sign that the mediation offered by FLIP requires recalibrations of context. As we watch wave frequencies scroll, I think back to the history of how waves came to be understood as spectral media in the first place.

\section{Waves across the Pacific}

Wave observations before World War II were not yet animated by a sense that waves might be sorted out by frequency-into a framework that would come to be called a wave spectrum, analogous to spectra of light, sound, or radio waves. Wave scientists had long known that waves were generated by ocean storms, which imparted energy to water and created swells that moved across the sea with definite wavelengths and periods. Rachel Carson, in The Sea around $U s$, summarized dominant scientific wisdom around midcentury:

As the waves roll in toward Lands End on the westernmost tip of England they bring the feel of the distant places of the Atlantic.... As they approach the rocky tip of Lands End, they pass over a strange instrument lying on the sea bottom. By the fluctuating pressure of their rise and fall they tell this instrument many things of the distant Atlantic water from which they have come, and their messages are translated by its mechanisms into symbols understandable to the human mind. If you visited this place and talked to the meteorologist in charge, he could tell you the life histories of the waves that are rolling in... He could tell you where the waves were created by the action of wind on water, the strength of the winds that produced them, how fast the storm is moving... Most of the waves ... he would tell you, are born in the stormy North Atlantic.... (Carson 1951, 113-14)

Such waves, it began to be surmised in the 1940 s, might be sorted out by their frequency (the inverse of their periods) into a spectrum. The intuition came from new communications media that had become part of scientists' everyday life-and from looking at these media from unusual angles.

British wave scientists during World War II lit upon the idea that it might be possible to "measure the variation of frequency with time" (Ursell, quoted in Longuet-Higgins 2010, 43) of wave records from a Lands End observing station and infer the geographical origins of waves with varied frequencies. Twenty-minute records of wave pressure, taken by undersea gauges, would be relayed to a rotating drum. But where a usual wave record might be rendered by a pen zigzagging lines on a rolling cylinder, here researchers turned to a method inspired by Hollywood. The director of "Group W," oceanographer George Deacon, recalled that colleague Jack Darbyshire

had a friend in the film industry and we learned that the Walt Disney film, 'Fantasia,' which was then a recent success, had the sound part of the film as black and white wavy silhouettes along the side of the picture frames. It therefore occurred to us that we 


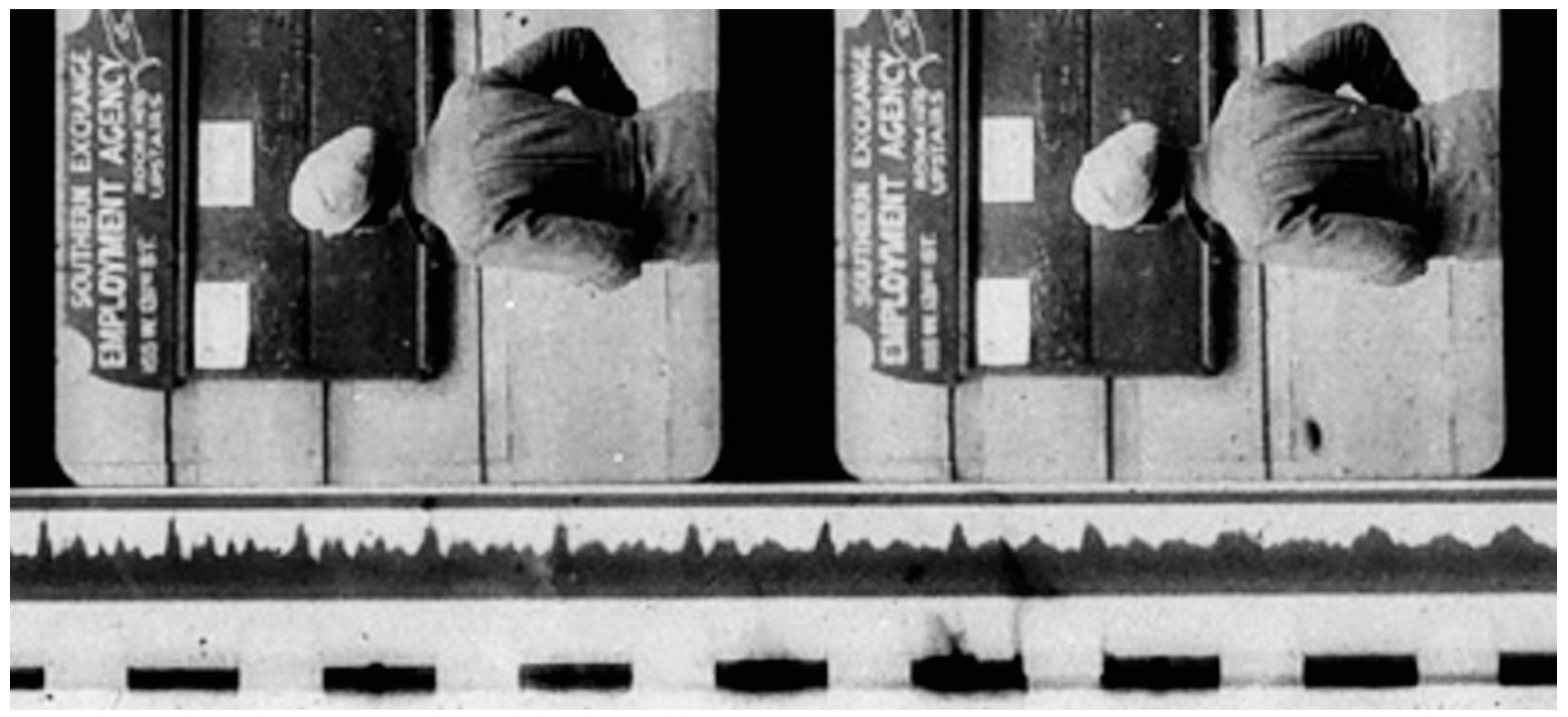

Figure 5: Film frames with accompanying “optical soundtrack," from the 1937 U.S. Works Progress Administration film, We Work Again. Preserved by the U.S. National Archives and Records Administration. National Archives Identifier: 12322; Local Identifier: 69.6

could do the same thing ... We could use [photographic] paper ... and instead of printing lines we would have a big block of light which would move about, generating a silhouette of the waves [see figure 7]. We could then put this on a wheel and, as the wheel spun round, the variations in black and white could be detected by a photocell. (quoted in Longuet-Higgins 2010, 50; and see Barber et al. 1946)

Deacon may also have been recalling the famous "meet the soundtrack" portion of Fantasia, in which animated frequency signatures shimmy onto the screen. The technique of optical sound had already been in use for some years (see figure 5)(Film, no surprise, had already shaped wave science-sequences of aerial photos of waves arriving at shores had already been mobilized to offer, mostly to the military, God's-eye flip-book views of seascapes [and see Kaplan 2018]).

Movies with sound were not the only media to inspire the spectral model. Oceanographer Willard Pierson adapted the spectrum model to wave records from the work of Bell Laboratories statistician John Tukey, who had used it to examine the statistical properties of noise in electronic circuits (Pierson and Marks 1952; Tukey and Hamming 1949). ${ }^{7}$ Tukey rendered waves as populations, not individuals, similarly to how sociology at the time was coming to study people (no coincidence, then, that Tukey later coauthored a review of

7 The spectral model had appeared earlier, in 1938, in "The Spectrum of Turbulence," in which G. I. Taylor starts with an analogy to light and prisms. 


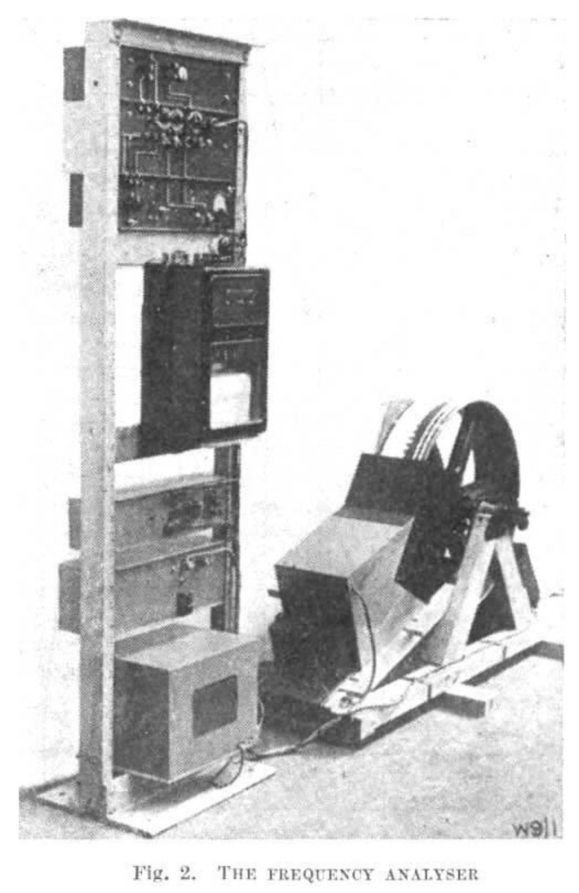

Figure 6: Figure 2 from N. F. Barber, F. Ursell, J. Darbyshire, and M. J. Tucker. 1946. "A Frequency Analyser Used in the Study of Ocean Waves.” Nature 158: 329-32.

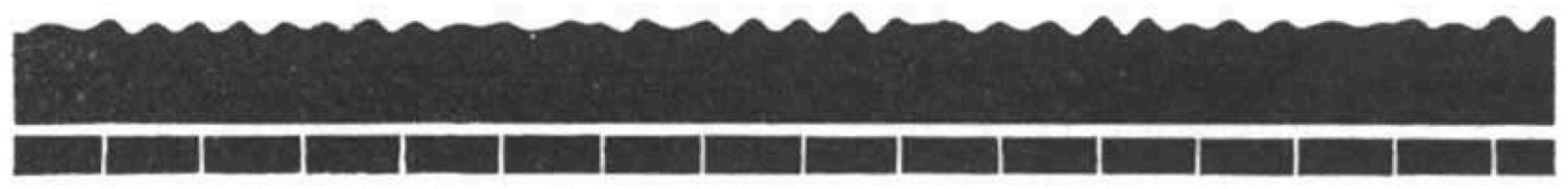

Fig. 1. A WAVE-PRESSURE RECORD

Figure 7: Figure 1 from N. F. Barber, F. Ursell, J. Darbyshire, and M. J. Tucker. 1946. "A Frequency Analyser Used in the Study of Ocean Waves.” Nature 158: 329-32.

the statistical underpinnings of the Kinsey report on sexual behavior [Cochran, Mosteller, and Tukey 1953]). In these borrowings, scientists turned to emergent media to understand the medium of the ocean; if water waves had once been the model for sound and electromagnetic waves, here researchers flipped the script, generating analogies back in the other direction.

The formalism of the wave spectrum makes ocean waves, in the elemental medium of seawater, thinkable as media in a communicative sense. As John Durham Peters $(2015,3)$ writes, "The old idea that media are environments can be flipped: environments are also media." Melody Jue argues in Wild Blue Media (2020) that oceanic phenomena, knowable through media (cameras, sonar, scuba, satellites), can themselves be profitably theorized as media, forces that crystallize as well as query conceptions about how information manifests as inscription, across interfaces, and in regimes of storage and transmission. 
Wave spectra came experimentally into focus in an ocean-spanning project during the summer of 1963 when Scripps oceanographer Walter Munk led Waves Across the Pacific, a project that tracked trains of waves from their origins in Antarctic storms across 10,000 miles of Pacific Ocean toward their arrival on the shores of Alaska. Munk was inspired in part by studies in radio astronomy, aimed at using diffraction patterns to locate the source of interstellar radiation (von Storch and Hasselmann 2010, 7). Munk, with eight other oceanographers, arrayed wave sensors at six sites across the Pacific (including one on FLIP). A 1967 documentary about the project (Dierbeck and Muheim 1967) lists the roster of locations (figure 8):

Cape Palliser Light in New Zealand, a rugged storm-battered point where the arrival of the great waves from an Antarctic storm could be expected;

Tutuila, one of the volcanic islands of Samoa, 2,100 miles to the Northeast;

the uninhabited equatorial atoll of Palmyra, 1,600 miles beyond Samoa, only two miles wide with no point of land more than six feet above sea level;

the easily accessible Kewalo basin in downtown Honolulu, selected for the central wave station and expedition headquarters;

the islandless North Pacific where the U.S. Navy's mobile island FLIP (Floating Instrument Platform) was stationed at 45 degrees north and 150 degrees west

and

the final recording site, an Alaskan beach, the end of the line for the trains of waves. ${ }^{8}$

The task was to follow waves as they traveled over a great arc spanning the Southern and Northern Hemispheres, with the hope of using this knowledge to improve wave and weather forecasting. The project required observing stations that could permit scientists to position pressure sensors on a not-toodeep seafloor (or, in the case of FLIP, on its stem, just below the surface). Sensors would need to be sensitive enough to measure waves as extensive as a mile long and as squat as a tenth of a millimeter high. Sensors translated changing water pressure into electrical signals, relayed to spooling computer punched tape (figure 9). 


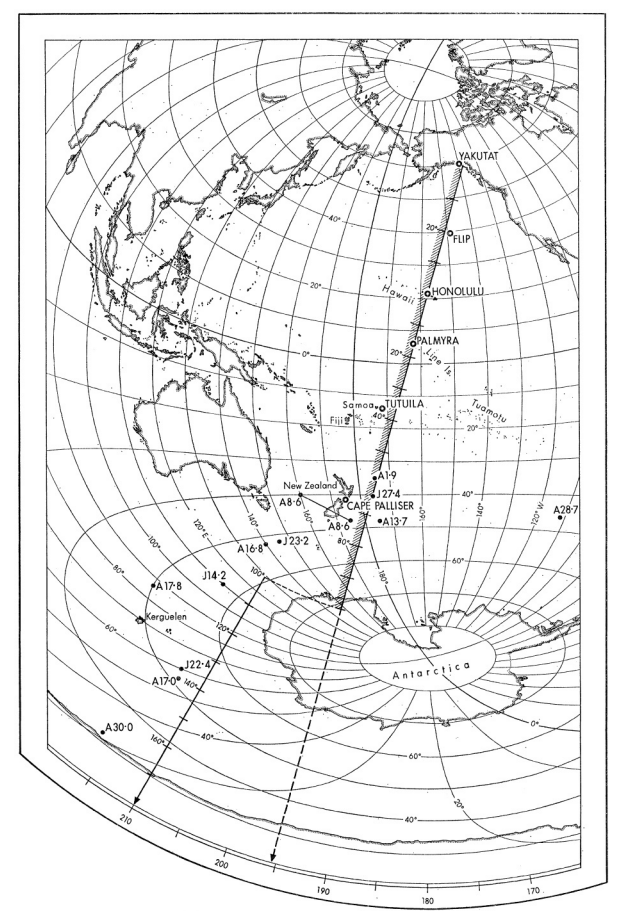

Figure 8: Figure 1 from F. E. Snodgrass, G. W. Groves, K. F. Hasselmann, G. R. Miller, W. H. Munk, and W. H. Powers. 1966. "Propagation of Ocean Swell across the Pacific." Philosophical Transactions of the Royal Society of London. Series A, Mathematical and Physical Sciences 259, no. 1103: 431-97.

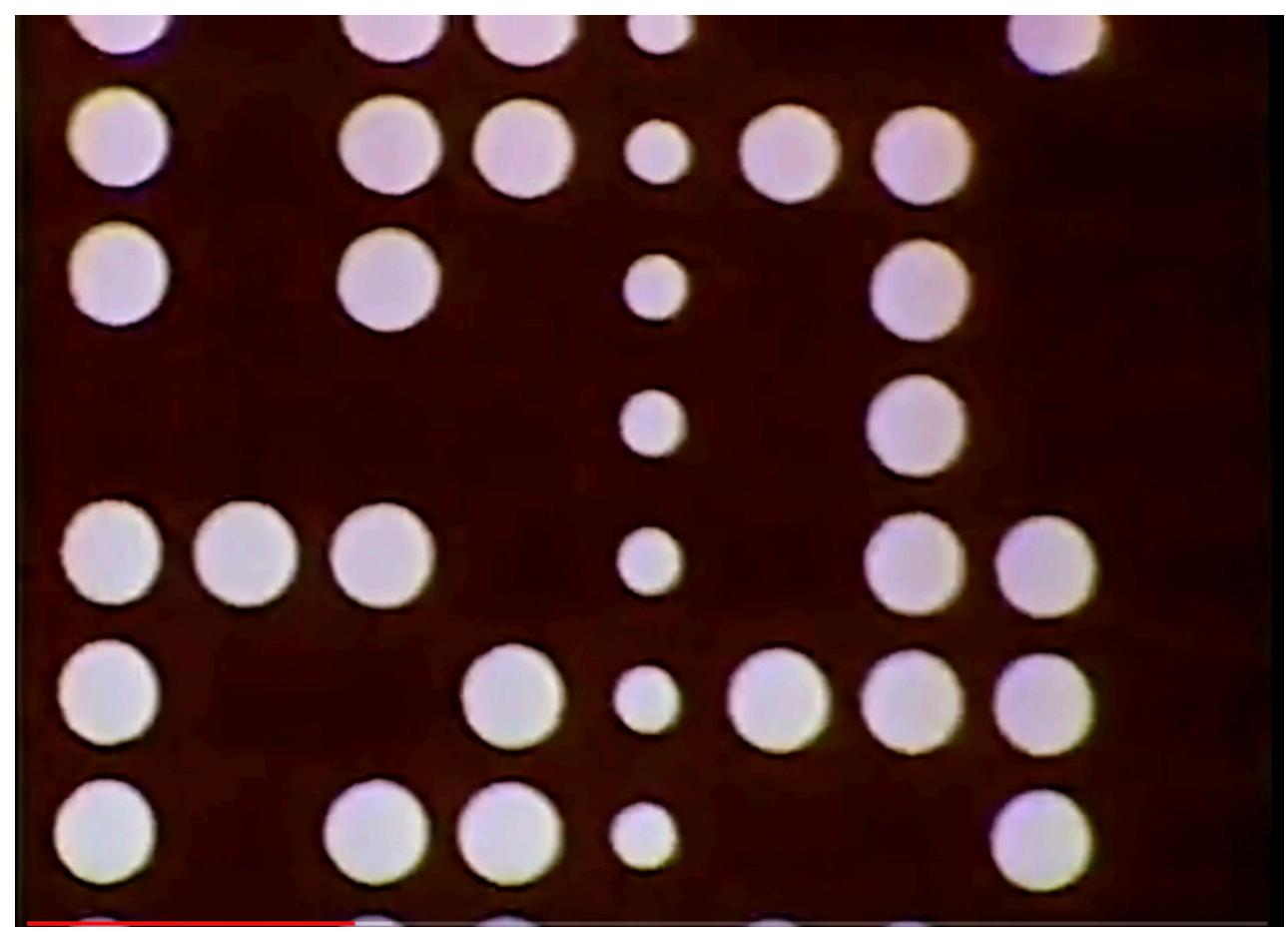

Figure 9: Close-up, punched-tape record of wave action, from Waves Across the Pacific. 
The Waves Across the Pacific film shows scientists unrolling punched-tape records onto graph paper and poking pencils through holes to make dots representing changing wave heights, producing graphs of the travel of waves. Such graphs permitted scientists to map patterns they hypothesized would become readable to stations later in the chain.

The tape data themselves were sent back to Scripps to be processed. As Munk put it in the film, spectral analysis could reveal how groups of waves traveled, since waves in the wild "are of all sizes and come from all directions. They are mixed and piled atop one another in lovely confusion." Translating punched tape into graphs, radioing, phoning, shipping, and more could generate spectra to sort it all out. The film shows the deployment of multiple sorts of media-tungsten wire, water, magnets, brass cylinders, globes, rulers, typewriters, filing cabinets, paper, pencils, punched tape, tape computers, telephones... all of which underscore the mediations through which waves come to be known. It is worth noting that in the film, all the in-the-field oceanographers are men; women-mostly secretaries, recordkeepers, some scientists-are on land, a gendered division of labor that was shaped by oceanography's use of sex-segregated navy infrastructure, by then-dominant US institutionalization of gender roles, and, as Naomi Oreskes has argued, masculinized notions of "heroic" sea science."

Taken as a whole, the Waves Across the Pacific project comes to render the Pacific Ocean into a giant transmitter of wave signals. The travel of its swells mimes the relay of information by scientists from one station to another. This ocean becomes akin to a radio, a wavy medium that stores and sends information about storms.

The Pacific, of course, is and was also a geopolitical medium. In Waves Across the Pacific, the script has Munk remark that, for this project, "the sea itself was our laboratory." This laboratory was available because, with the exception of New Zealand, most points along the great circle had come, since World War II, to be under American rule, either as territories of the United States (Tutuila, on American Samoa, and Palmyra) or as states (Hawaii and Alaska). As Michael Reidy and Helen Rozwadowski argue,

knowledge of the ocean was-and remains-inextricably connected to midcentury geopolitics and the growth of modern science.... [T] he expansion of empire enabled scientists... to study topics that required the accumulation and subsequent reduction, tabulation, and graphing of large amounts of observational data from all over the globe. $(2014,351,350)$

\footnotetext{
9 See Oreskes 1996, 2000, on the historical marginalization of women scientists at Scripps, often accomplished through assigning them to important, but low-status, tasks such as working, on land, to figure out the meaning of deep-sea temperature records. See also Day 1999, on an explicit Scripps policy enacted in 1949 that forbade women from taking passage on overnight cruises. Such policies were overturned in the
} 1960s, though disparities persisted. 
Ruth Oldenziel, writing of US island territories as an array of "naval nodes for the control of ocean space" $(2011,16)$, reads the Pacific Ocean as layering communications infrastructures, military outposts, and colonial enterprise. The geopolitical context that made Waves Across the Pacific possible is left unarticulated in the film. The film's narrator instead paints a picture of the Pacific as a space of nature, with scientists tracking
waves that propagate across the entire Pacific, the largest body of water on our planet, waves that are interrupted only occasionally by the upthrust of a lonely coral atoll, waves that smash endlessly against the rock of high volcanic islands like Samoa, waves which ten days later die quietly on the beaches of distant coasts, the end of a journey half around the world.

These waves, however, also move through geopolitical space. The "lonely coral atoll” of Palmyra was occupied by the US Navy from 1939 to 1959, during which time the navy built a runway and dredged a ship channel, after which the island was used, in 1962, as a site from which the Department of Defense observed nuclear tests above nearby Johnston Atoll. The waves that "smash endlessly against the rock of high volcanic islands like Samoa" meet not just a shore but also a Marine Corps outpost. And the "distant coast" of the experiment is in Alaska, which had just in 1959 became a US state. When the script (written by freelance writer Harry Miles) has Munk casually say, about the experiment, "We preferred islands we could get to," it leaves to one side the historical contexts that made these places available-particularly those to do with the hydrocolonial enterprises (Bystrom and Hofmeyer 2017) that saw the United States extend its geopolitical maritime reach.

Let me flip the script and make explicit how the film represents island environments as wild nature, emphasized through images of fieldworking oceanographers-white men-often in shorts, wearing no shirts, sometimes sporting tropical bead necklaces. A scene of Munk in American Samoa- "along the exotic southwestern shore of Tutuila"-shows him aided by shirtless local men placing a sensor underwater (and see figure 10). He works with tape records in a fale, a "house... built entirely of coconut palm, an ideal place to work with waves," and, his voice-over tells us, later in the film, as we see him reading a book on a veranda, "Data taking became quite routine. My wife and some of the Samoans learned to operate the recording equipment." The film's positioning of local people (and some American women) as help for male scientists also appears elsewhere; in Alaska, Gaylord Miller, working at a Coast Guard station, and "the only one of us who sometimes met a bear on his way to work," employs "a fishing boat operated by an Eskimo crew" to position a sensor. As if to underscore the vacation South Pacific sites represented for white scientists, we see many with newly grown beards. Though Munk and other participants in the project had more complex relations in person and on the ground than were captured on camera - Munk's wife Judith's letters to 




Figure 10: "Measuring ocean swell from a Fale in Tutuila, American Samoa (1963). Walter had persuaded Judith to take the 0400 daily watch of swell recording. (Edie, Kendall, Judith, Walter, and Silau playing the guitar)." From von Storch and Hasselmann 2010, figure 1.2, p. 8.

her parents, written from Tutuila in 1963, are worth a look ${ }^{10}$ - the filmmakers drew upon tropes representing Pacific Islanders in Cold War Hollywood films as docile "natives" (see Hereniko 1999), giving viewers scientists and waves with lives (recall Carson's "life histories of the waves"), but not local or indigenous people.

FLIP, meanwhile, "at her lonely north Pacific station," is a space of pure technology: "Wave measurements aboard FLIP were comparable and in some ways better than those on land. FLIP floated with negligible drifting taking wave measurements for three hours twice a day." FLIP becomes what Helen Rozwadowski and David van Keuren (2004) might call "a machine in Neptune's garden," drawing here on Leo Marx's analysis, in The Machine in the Garden, of how American pastoral landscapes have come to enfold and include modern technology (think bucolic scenes of railroad trains in the countryside). FLIP as an avatar of science comes to fit right in to wild ocean space, both within and apart from it, bobbing at the elemental interface of air and water.

10 See letters from Judith Munk to her parents, Winter Davis Horton and Edith Kendall Horton, in Judith Horton Munk Papers, 1962-1968, accession no. 93-18, box 1, folder 3, Scripps Institution of Oceanography Archives. See also the biography of Helen Hill Raitt (Day 1997), wife of geophysicist Russell Raitt, who cofounded UC San Diego's International Center and who in 1952 flew to meet her husband during a Pacific voyage, after which she developed a long career of advocating for Tongan language library and publishing infrastructure. See also Dutton 1999 , 76-79. For an Indigenous view of Cold War science in Oceania-particularly in the Marshall Islands, where U.S. nuclear weapon "test” detonations enlisted oceanographers (Rainger 2004)—see Jetñil-Kijiner 2017. 


\section{A Turn to Wonder}

But FLIP is a weird machine in the garden. Its serious side is doubled by the sideways flippiness of the thing. It awakens in scientists a sense of wonder. That sense is in part amazement about what engineers can build—and astonishment that funding could have been gathered to build such a bizarre device. But it also derives from a disorienting but welcome affirmation, for people invested in an ethos of objectivity, that the embodied perspective of humans is conventional - that answering questions always requires a frame of reference and that that frame can, under the right circumstances, be shifted.

FLIP offers an instantiation of a meta-objective standpoint, one in which the relative coordinates of human experience nest within a grid of absolute values in which "up" and "down" are orientations, not ontologies. David Valentine, in ethnographic work among space travel enthusiasts, observes that the aspirational space tourists he knows think relativistically about gravity: in zero $\mathrm{g}$, on other planets, and on hypothetical circular space stations that might produce artificial gravity through the centrifugal force of rotation. Gravity, suspended and reorganized, puts for them its status as a "universal universal" - as a ground-into question $(2017,191)$. On FLIP, of course, where gravity never goes away but just shifts experiential direction, disorientation highlights the limited perceptual tuning of humans-a tuning that can be outsourced to observing instruments that can flip axes without getting confused. ${ }^{11}$

Still, the moment of the "flip" is, for scientists, one of suspended expectation, an interstitial moment of wonder. After a while, some of the science party are feeling sorry for me because I missed the flip. People are eager to share experiences.

One declares that the flip was "Pretty cool! The actual flipping was holding onto the rail-a little bit like a rollercoaster, bobbing up and down, very dynamic. Felt pretty safe, but it's kind of a novel thing, you don't see a ship go vertical, I guess. Something you're not supposed to do with a ship.” Another remarks, "We were giggling like kids. The momentum when it righted itself-it's like a mixture of excitement and oh shit, this could be the time that FLIP has a catastrophic accident. It became a big metal tree house, like the Lost Boys had in Peter Pan.”

Indeterminate, shifting gravity, observes anthropologist Debbora Battaglia in her reading of astronaut diaries, is often experienced as a zone of levity. Examining the diary of a Soviet cosmonaut perplexed when he "came in at an unusual angle" upon arriving (through an airlock) into a space station, Battaglia notes that defamiliarization and perspectival shifts are often managed

11 Jue (2020) takes human disorientation in and at sea as a key starting point in Wild Blue Media, her brilliant book on "thinking through seawater.” 
through joking (2012). As if to confirm that analysis, scientists on FLIP receive a "certificate of flipping," complete with calligraphy suggesting an antique age of sail-something like those tongue-in-cheek documents that sailors get when they cross the equator. FLIP is, of course, a playful (even flip) backronym that rotates attention away from the serious-sometimes deadly serious, military - research that has been done on the platform.

In her anthropology of wonder, The Cow in the Elevator, Tulasi Srinivas (2018) reminds us that the Oxford English Dictionary defines wonder as "the emotion excited by the perception of something novel and unexpected." The pivoting elevator that is FLIP excites just that emotion among scientists (crewmembers, particularly the cook, are less enchanted; wonder, like "heroism," can emerge only against a scaffold of maintenance and support [Steinhardt 2018]). But wonder does not occupy some space outside objectivity; it is part of it, a resource and oscillating opposite to it. This is not the full upside-down turn that would have wonder as the flip side of a deracinated objectivity. Rather, it is as that which poses wonder as ever-coming-into-and-out-of-alignment with empirical accounting, as that which makes measure meaningful. Whether FLIP is rabbit or duck depends on what scientists ask to see. Think of the flip, then, as an epistemological turn, with the imaginative and the empirical always conjoined, though always rotating in and out of alignment.

The platform is not a vantage for what historian Lorraine Daston (1992) once called aperspectival objectivity but is rather an aerie offering a hovering, provisional, and located frame of reference, a view not from nowhere but from a close by and controlled somewhere - though one that might later be factored out, to leave only wave measurements, reinstating a view from outside or above, a situated knowledge (Haraway 1991) edging toward the aspirationally unsituated.

\section{Beholding the Waves}

If, as I have argued, models of ocean waves often bear the traces of the media with which they have been measured, imagined, and compared-becoming doubles or afterimages of, say, radio waves-it is when waves break in the open ocean that analogies to other kinds of waves often break down and, indeed, when the material capacities of seawater as a holder of heat and as an aerosolizing medium begin to exceed formal models of waves as mere curvilinear pattern.

Understanding the matter of breaking waves is a question that keeps scientists on FLIP up at night-because it is a question they often ask at night, when they do not have to deal with the turbulence caused by sunlight on the waterair interface. "The sun for me is noise," Moscow-born, Florida-trained oceanographer Ivan Savelyev tells me. Working at night, he avers, makes the open-ocean "field" more like a "lab," where variables are controlled-and, indeed, the flip of the platform from horizontal to vertical makes the vessel not so much immersed in a field as floating above it. I have run into Savelyev 




Figure 11: An infrared image, from above, of waves on 1.5 square meters of sea surface, striped with laser lines projected to track patterns of turbulence. Courtesy of Ivan Savelyev.

as he is starting his day, at 5 p.m. His instrument, on the starboard boom, features two midwave infrared cameras pointed down at the ocean surface onto an area of 1.5 square meters. Onto this patch of sea, Savelyev projects beams of infrared laser light-light just below the visible spectrum-that he has arranged into grids, points, and lines. He images those lines through two cameras (to compose a stereo image) whose feeds he can translate into visibility on his laptop in FLIP's science lab (see figure 11 for an image from one screen-we look down here onto the sea surface, striped with infrared-and see Savelyev and Fuchs 2018).

The lines wriggle on the sea surface, revealing patterns of turbulence. Infrared light, which reveals heat signatures, lingers for a moment after it hits a surface, leaving slurring traces that track the motion of water. It is almost as though Savelyev's apparatus enacts an ancient Greek theory of vision that has eyes shooting beams out at the world to know, to be-bold, it. Anthropologist Veronica Strang suggests that "Wonder comes from all sorts of light. People tend to appreciate unusual light phenomena such as sunrises and sunsets, rays from behind clouds, exciting color contrasts, and rainbows" (quoted in Henderson 2014). And infrared. The images, which warp like syrup, relay the material otherness of the sea, even as their eeriness emerges from algorithmic data conversions first developed for night vision surveillance (Parks 2014). But while these look like otherworldly waves, waves with invisible lives, they are also waves that, known through the thermoception of infrared, are very much of 

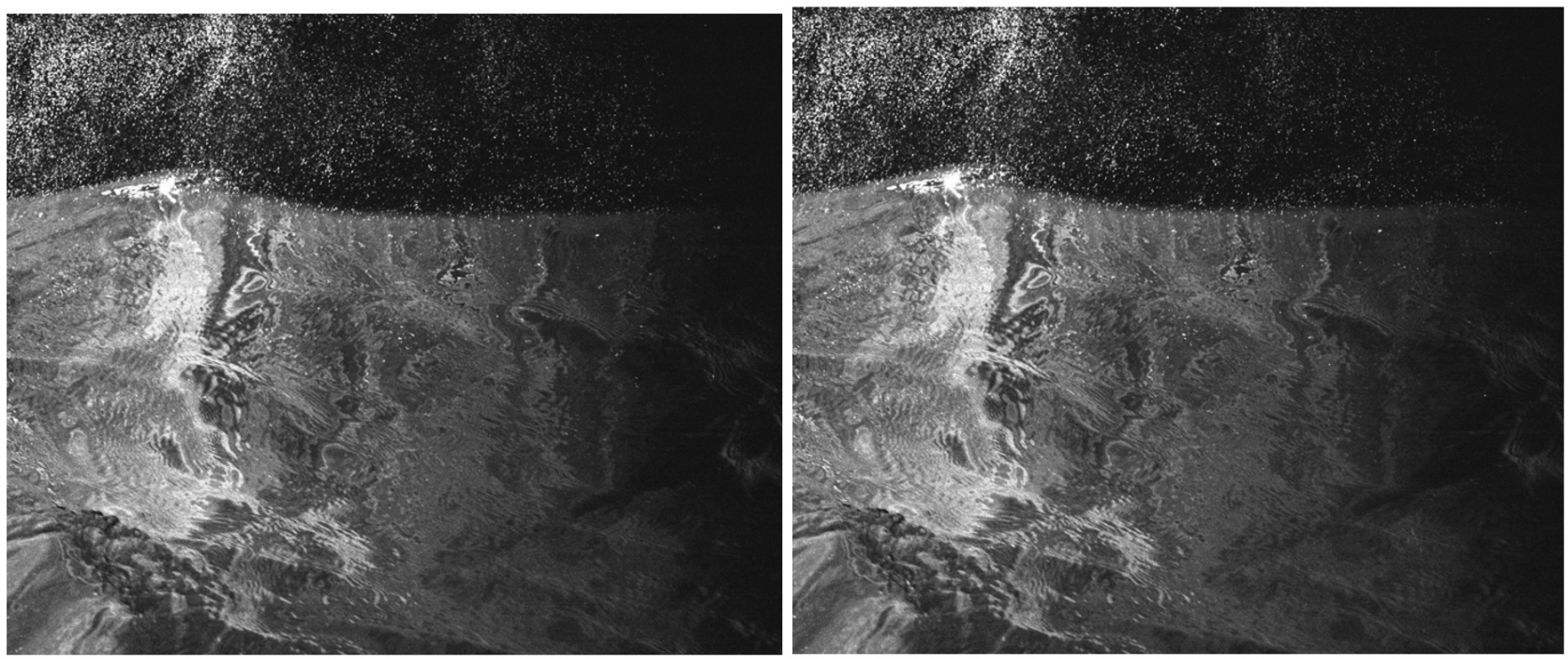

Figures 12a and 12b. Two sequential images of cross-sectioned waves, imaged with laser light. Courtesy of Marc Buckley.

our moment, when tracking the exchange of temperature across the interface of water and air may be key to understanding what media theorist Nicole Starosielski (2019) calls the "intense thermal volatility" of climate change.

One of Savelyev's colleagues on board, Marc Buckley, a French American postdoc, is also interested in wind-wave interactions. ${ }^{12} \mathrm{He}$ has stationed cameras that point obliquely at the sea surface below the boom. Nearby, he has positioned a fog generation system, sending water particles dancing in the air above the waves. To take freeze-frame photos of this dance, he has installed a laser-beam generator that, through beam manipulation, creates a sheet of green light that slices down through the air, reflecting off fog particles, permitting him to capture 10-nanosecond cross-section snapshots of waves and to visualize the airflow above them. Figures $12 \mathrm{a}$ and $12 \mathrm{~b}$ show two sequential images, 0.5 milliseconds apart (see Buckley and Veron 2019). Buckley likes these images because they remind him of Hokusai's Great Wave off Kanagawa. They remind me, too, of old flip-books, though now operating at insane speed, creating quantities of images feasible because of increasing magnitudes of data storage.

This experiment, like Savelyev's, makes it necessary, if one heads outdoors from the ship's science lab, to put on goggles to block the wavelength of possibly reflecting laser light. I go outside with goggles and, as expected, cannot see the laser. But when I hold up my camera to take a photo, I see green through the screen, even through my safety lenses. Savelyev says my camera is lying to me, relaying a different wavelength. Before I can get too far in any reverie about wonder and the unseen, Buckley gives me a nothing-magical-here 
account of what we're seeing. His explications turn off the wonder switch: everything might be set against a grid of objective metrics, including those fluxional entities known as waves.

\section{Paradigm Scripts}

What is all this research for? It is about making unseen sea territories readable, and, as Naomi Oreskes (2003) has argued, civil and military motives are intertwined - though these often flip in and out of focus, oscillating between being figure and being ground. Scientists have accommodated to the alternately loose and tightly coupled-with-the-navy funding structure, to the social form of scientific research that may lead to "dual-use technology" (Smit 1995): technology with both quotidian public and military application. I ask them directly about it. One tells me:

I don't find it relevant whether research is funded by NSF or ONR. What I mean by that is that ONR funds basic research that benefits science. Any basic physics research can have military applications. Any basic research, actually. In a way, I'm quite thankful that NSF and ONR are funding basic research. I'm more of a pacifist, if people are funding basic research in a nice way, and giving scientists freedom to do things, it is a good thing. It's public research, it's not classified, our results are published.

Another says that although their work is funded by ONR, "what I understand and what I research is pretty far from what can be used offensively. Most of it will be weather, and it will be public." I recall the argument of Chandra Mukerjee's 1989 A Fragile Power: Scientists and the State: that many militaryfunded civilian scientists have a sense of their work as too complex or unpredictable for immediate application. The structure of feeling this creates, Mukerjee argues, is one in which scientists secure a sense of themselves as objective, not beholden to instrumental aims of their funding. This subjectification generates disinterestedness as a social resource upon which state spokespeople can then call as an epistemological resource to back up political arguments. As scientists flip frames of reference between subjective and objective-think of Wittgenstein's duck and rabbit, of FLIP's flip from levity to seriousness, of oscillations between mundanity and the excitement of being at sea-they operate within what I want to call paradigm scripts: modes of thinking that take for granted the possibility of seeing things one way and then another. ${ }^{13}$

Flipping such scripts can be generative of modes of seeing science and its relation to society. To point this out is not to presume to know or challenge individual scientists' full or most personal motives, which exceed any neat

13 I riff here on Thomas Kuhn's notion of the paradigm shift (1962), his phrase for a decisive switch in a scientific community from one frame of seeing and thinking about problems to another. 
social analysis. Rather, it is to point to the operation of the shifting frames of references within which they (and many of us) find themselves/ourselves, and to the effects of such operations. Flipping the paradigm script between "pure" and "applied," for example, can create a sense of scientific time as both lagging behind and racing ahead of political time. ${ }^{14}$

Scientific time, for wave science, unfolds in two further registers: first, in the longue durée time of accumulating scientific knowledge production, but second, in the ever-repeating, looping, and repeating time of putatively perpetual wave time (measured in milliseconds or minutes, in the time it takes for wave cycles to recur or dynamics to unfold - though that time can be interrupted, as it was for a period during my time on FLIP when the Orange County Canyon Fire 2 generated smoke that might confound data gathering). It is that second kind of time-cyclical time-that can make waves so difficult to apprehend as bearing the marks of the media histories that have made them readable.

Wave science, so invested in prediction, offers to its practitioners orientations toward possible futures (Bryant 2016)_for their science, for their careers, for the ocean world they study. "Orientations," writes Sarah Ahmed, "shape not only how we inhabit space, but how we apprehend this world," "how we proceed from 'here,' which affects how what is 'there' appears” $(2006,3,8)$. At stake in researchers' orientations are visions of the relation of objectivity to politics, the line or relation between science and society, what it means to be a good scientist, and, of course, what counts as interesting wave science. In spite of its popular nickname ("the FLIP ship"), FLIP is not a ship. It is more like a -ship: that conceptual operator (used as a word-forming element in such terms as "friendship" or "kinship") that points to a condition or a "relation between." Flipping the -ship reveals those relations to be mediations and those mediations always to be matters of orientation, all the way around.

\section{COVID-19 Addendum}

When COVID-19 became a matter of concern in the United States, Scripps scientists were asked by some Southern California communities whether the coronavirus might travel in aerosols spooling off from ocean waves, a question preoccupying beachgoers, surfers, and civic leaders. Atmospheric chemist Kim Prather-founder and director of the National Science Foundation Center for Aerosol Impacts on Chemistry of the Environment, based at Scripps-early on took a cautious stance, drawing on her expertise in tracking ocean aerosols and reading them for signs of anthropogenic climate change (see Xia 2020). Meanwhile, she also reoriented some of her research, directly investigating

14 Compare Traweek 1988 on high-energy physicists' calibration of their scientific, biographical career times to the "beamtime" they are able to secure on particle detectors. 
how to reduce transmission of SARS-CoV-2 between people (Prather, Wang, and Schooley 2020). If, as I have argued here, waves and their effects have been apprehended through and have taken on qualities of the media used to understand and model them-from animated film to spectrally sorted radio transmission-here, the medium of aerosolized seawater, created by wave whitecapping and breaking, prepares the way for new inquiries into disease transmission, as scientists such as Prather flip their questions-here, asking not just about the effects on people of air-water media (surf) but also about the effects of people as themselves air-water media (Scripps itself issued new guidelines on how to safely conduct seagoing operations, which were halted on March 17, 2020, and resumed on July 1, 2020 [https://scripps.ucsd.edu/ships/ novel-coronavirus-covid-19-information-sio-research-vessels]).

\section{Acknowledgments}

I begin by thanking meteorologist Qing Wang, chief scientist on the FLIP trip I was able to join. She made it possible for me to meet the other members of the FLIP science party whom I must thank-Marc Buckley, David OrtizSuslow, and Ivan Savelyev-as well as a number of additional scientists whom I do not here name but who were also above-and-beyond generous during the voyage. I also thank FLIP captain Tom Golfinos and the platform's crew. At the Scripps Institution of Oceanography, I thank Matthew Alford, Sophia Merrifield, Robert Pinkel, and Nick Pizzo for invaluable on-land guidance on how to think about the science and history made from FLIP. I am very grateful to Ken Melville, who passed on in 2019, for essential conversations on the history of wave science and for kindly brokering my presence on FLIP. An early conversation with Walter Munk, who generously gave me a couple of hours of his time early on in this project, was also immensely helpful. UCSD Special Collections librarian Heather Smedberg was an expert guide into the Scripps archive. I presented portions of this material in the Climate, Atmospheric Sciences, and Physical Oceanography Seminar Series at Scripps in June 2019, and I thank the audience members for their comments. This account has also benefited from careful readings by Nikhil Anand, Andrea Ballestero, Lucas Bessire, Timothy Choy, Daniel Fisher, Jacob Hamblin, Lilly Irani, Melody Jue, Naveeda Khan, Jessica Lehman, Joe Masco, Nicole Nelson, Heather Paxson, John Durham Peters, Helen Rozwadowski, Tulasi Srinivas, Nicole Starosielski, and Mei Zhan. Wolf Kittler, Christina Vagt, and Sebastian Vehlken, the organizers of the October 2019 Modeling the Pacific Conference at UC Santa Barbara upon which this special issue draws, were excellent editors. I also thank the two anonymous reviewers.

\section{Transparency Statement}

The author has no conflicts of interest of which they are aware. 


\section{REFERENCES}

Ahmed, Sara. 2006. Queer Phenomenology: Orientations, Objects, Others. Durham, NC: Duke University Press. https://doi.org/10.1515/9780822388074.

Barber, N. F., F. Ursell, J. Darbyshire, and M. J. Tucker. 1946. "A Frequency Analyser Used in the Study of Ocean Waves." Nature 158 (4010): 329-32. https://doi.org/10.1038/158329a0.

Barthes, Roland. 1974. S/Z. Translated by Richard Howard. New York: Hill and Wang.

Battaglia, Debbora. 2012. "Coming in at an Unusual Angle: Exo-Surprise and the Fieldworking Cosmonaut.” Anthropological Quarterly 85 (4): 1089-1106. https://doi.org/10.1353/ anq.2012.0058.

Bryant, Rebecca. 2016. “On Critical Times: Return, Repetition, and the Uncanny Present.” History and Anthropology 27 (1): 19-31. https://doi.org/10.1080/02757206.2015.1114481.

Buckley, Marc P., and Fabrice Veron. 2019. "The Turbulent Airflow over Wind Generated Surface Waves.” European Journal of Mechanics - B/Fluids 73 (January): 132-43. https://doi.org/10.1016/ j.euromechflu.2018.04.003.

Bystrom, Kerry, and Isabel Hofmeyer. 2017. "Oceanic Routes: (Post-It) Notes on HydroColonialism.” Comparative Literature 69 (1): 1-6. https://doi.org/10.1215/00104124-3794549.

Carson, Rachel L. 1951. The Sea Around Us. Oxford: Oxford University Press. http://www.rachelcarson.org/SeaAroundUs.aspx.

Cochran, William G., Frederick Mosteller, and John W. Tukey. 1953. "Statistical Problems of the Kinsey Report.” Journal of the American Statistical Association 48 (264): 673-716. https://doi.org/ $10.1080 / 01621459.1953 .10501194$.

Daston, Lorraine. 1992. "Objectivity and the Escape from Perspective.” Social Studies of Science 22 (4): 597-618. https://doi.org/10.1177/030631292022004002.

Day, Deborah. 1997. "Helen Hill Raitt Biography." La Jolla, CA: UCSD Libraries. http://scilib.ucsd.edu/sio/biogr/Raitt_Helen_Biogr.pdf.

- - . 1999. "Overview of the History of Women at Scripps Institution of Oceanography." Presented at the UCSD Women's Center Panel, October 14.

Dierbeck, Robert, and Harry Miles Muheim. 1967. Waves Across the Pacific. McGraw-Hill Text-Films.

Dutton, Lee S., ed. 1999. Anthropological Resources: A Guide to Archival, Library, and Museum Collections. New York: Garland Publishing.

Fisher, Fred H., and Fred N. Spiess. 1963. "Flip-Floating Instrument Platform.” The Journal of the Acoustical Society of America 35 (10): 1633-44. https://doi.org/10.1121/1.1918772.

Haraway, Donna. 1991. "Situated Knowledges: The Science Question in Feminism and the Privilege of Partial Perspective.” In Simians, Cyborgs, and Women: The Reinvention of Nature, 183-202. New York: Routledge.

Henderson, Caspar. 2014. "Why Light Inspires Ritual.” Nautilus 11. http://nautil.us/issue/11/light/ why-light-inspires-ritual.

Hereniko, Vilsoni. 1999. "Representations of Pacific Islanders in Film and Video.” Documentary Box 14. https://www.yidff.jp/docbox/14/box14-3-e.html.

Jetñil-Kijiner, K. 2017. “Two Degrees.” In Iep Jaltok: Poems from a Marshallese Daughter. Tucson: University of Arizona Press.

Jue, Melody. 2020. Wild Blue Media: Thinking Through Seawater. Durham, NC: Duke University Press. https://doi.org/10.1515/9781478007548.

Kaplan, Caren. 2018. Aerial Aftermatbs: Wartime from Above. Durham, NC: Duke University Press. Kuhn, Thomas S. 1962. The Structure of Scientific Revolutions. Chicago: University of Chicago Press. 
Longuet-Higgins, Michael. 2010. "Group W at the Admiralty Research Laboratory.” In Of Seas and Ships and Scientists: The Remarkable Story of the UK's National Institute of Oceanography, edited by Anthony Laughton, John Gould, "Tom” Tucker, and Howard Roe, 41-66. Cambridge: Lutterworth Press.

Mukerjee, Chandra. 1989. A Fragile Power: Scientists and the State. Princeton, NJ: Princeton University Press.

Oldenziel, Ruth. 2011. "Islands: The United States as a Networked Empire." In Entangled Geographies: Empire and Technopolitics in the Global Cold War, edited by Gabrielle Hecht, 13-42. Cambridge, MA: MIT Press. https://doi.org/10.7551/mitpress/9780262515788.003.0002.

Oreskes, Naomi. 1996. "Objectivity or Heroism? On the Invisibility of Women in Science." Osiris 11 (January): 87-113. https://doi.org/10.1086/368756.

- - . 2000. “'Laissez-Tomber': Military Patronage and Women's Work in Mid-20th-Century Oceanography.” Historical Studies in the Physical and Biological Sciences 30 (2): 373-92. https://doi.org/10.2307/27757836.

- - . 2003. "A Context of Motivation: U.S. Navy Oceanographic Research and the Discovery of Sea-Floor Hydrothermal Vents." Social Studies of Science 33 (5): 697-742. https://doi.org/10.1177/ $\underline{0306312703335004 .}$.

Parks, Lisa. 2014. "Drones, Infrared Imagery, and Body Heat." International Journal of Communication 8: 2518-21.

Peters, John Durham. 2015. The Marvelous Clouds: Towards a Philosophy of Elemental Media. Chicago: University of Chicago Press. https://doi.org/10.7208/chicago/9780226253978.001.0001.

Pierson, Willard J., and Wilbur Marks. 1952. "The Power-Spectrum Analysis of Ocean-Wave Records." Transactions of the American Geophysical Union 33 (6): 834-44. https://doi.org/ 10.1029/tr033i006p00834.

Prather, Kimberly A., Chia C. Wang, and Robert T. Schooley. 2020. "Reducing Transmission of SARS-CoV-2.” Science 368 (6498): 1422-24. https://doi.org/10.1126/science.abc6197.

Rainger, Ronald. 2004. "A Wonderful Oceanographic Tool”: The Atomic Bomb, Radioactivity and the Development of American Oceanography." In The Machine In Neptune's Garden: Historical Perspectives on Technology and the Marine Environment, edited by Helen Rozwadowski and David K. van Keuren, 96-132. Sagamore Beach, MA: Science History Publications.

Reidy, Michael S., and Helen M. Rozwadowski. 2014. "The Spaces In Between: Science, Ocean, Empire.” Isis 105 (2): 338-51. https://doi.org/10.1086/676571.

Rozwadowski, Helen M. 2004. "Engineering, Imagination, and Industry: Scripps Island and Dreams for Ocean Science in the 1960s." In The Machine in Neptune's Garden: Historical Perspectives on Technology and the Marine Environment, edited by Helen M. Rozwadowski and David K. van Keuren, 315-53. Sagamore Beach. MA: Science History Publications.

Rozwadowski, Helen M., and David K. van Keuren, eds. 2004. The Machine in Neptune's Garden: Historical Perspectives on Technology and the Marine Environment. Sagamore Beach. MA: Science History Publications.

Savelyev, Ivan, and Julian Fuchs. 2018. "Stereo Thermal Marking Velocimetry.” Frontiers in Mechanical Engineering 4 (February). https://doi.org/10.3389/fmech.2018.00001.

Scripps Institution of Oceanography. n.d. "History of FLIP.” Accessed January 14, 2019. https://scripps.ucsd.edu/ships/flip/history.

Smit, Wim A. 1995. "Science, Technology, and the Military: Relations in Transition.” In Handbook of Science and Technology Studies, edited by Sheila Jasanoff, Gerald E. Markle, James C. Peterson, and Trevor Pinch, revised edition, 598-626. Thousand Oaks, CA: Sage Publications. 
Snodgrass, F.E., G.W. Groves, K.F. Hasselmann, G.R. Miller, W.H. Munk, and W.H. Powers. 1966. "Propagation of Ocean Swell across the Pacific." Philosophical Transactions of the Royal Society of London. Series A, Mathematical and Physical Sciences 259 (1103): 431-97.

Srinivas, Tulasi. 2018. The Cow in the Elevator: Anthropology of Wonder. Durham, NC: Duke University Press.

Starosielski, Nicole. 2019. “Infrared.” Environmental Planning D: Society and Space. https://www.societyandspace.org/articles/infrared.

Steinhardt, Stephanie. 2018. "The Instrumented Ocean: How Sensors, Satellites, and SeafloorWalking Robots Changed What It Means to Study the Sea.” PhD diss., Communication, Cornell University.

Storch, Hans von, and Klaus Hasselmann. 2010. Seventy Years of Exploration in Oceanography: A Prolonged Weekend Discussion with Walter Munk. Berlin: Springer-Verlag.

Taylor, G.I. 1938. "The Spectrum of Turbulence.” In Proceedings of the Royal Society of London, Series A: Mathematical and Physical Sciences, 164:476-90.

Traweek, Sharon. 1988. Beamtimes and Lifetimes: The World of High Energy Physicists. Cambridge, MA: Harvard University Press.

Tukey, John W., and Richard W. Hamming. 1949. Measuring Noise Color 1. Memorandum MM-49-110-119. Murray Hill, NJ: Bell Telephone Laboratory.

Valentine, David. 2017. “Gravity Fixes: Habituating to the Human on Mars and Island Three." HAU: Journal of Ethnographic Theory 7 (3): 185-209. https://doi.org/10.14318/hau7.3.012.

Wang, Qing et al. 2019. "Sampling Spatial-Temporal Variability of Electromagnetic Propagation in CASPER-West." In Proceedings of 13th European Conference on Antennas and Propagation. Krakow, Poland. https://ieeexplore.ieee.org/document/8740189.

Waters, Hannah. 2012. “FLIP: The Floating Instrument Platform.” Smithsonian Ocean. https://ocean.si.edu/human-connections/exploration/flip-floating-instrument-platform.

Wittgenstein, Ludwig. 1953. Philosophical Investigations. Translated by G.E.M. Anscombe. Oxford: Basil Blackwell.

Xia, Rosanna. 2020. "Is There a Greater Risk of Coronavirus Spread at the Beach? Scientists Aren't Sure.” Los Angeles Times, April 11, 2020. 